\title{
Common ultrasound and contrast-enhanced ultrasonography in the diagnosis of hepatic artery pseudoaneurysm after liver transplantation
}

\author{
XIUYUN REN ${ }^{1,2}$, YUKUN LUO ${ }^{2}$, NONG GAO $^{2}$, HONG NIU $^{2}$ and JIE TANG ${ }^{1}$ \\ ${ }^{1}$ Department of Ultrasound, The General Hospital of Chinese People's Liberation Army, Beijing 100853; \\ ${ }^{2}$ Department of Ultrasound, The General Hospital of Chinese People's Armed Police Forces, Beijing 100039, P.R. China
}

Received March 3, 2016; Accepted May 17, 2016

DOI: $10.3892 /$ etm.2016.3343

\begin{abstract}
The diagnostic value of common ultrasound and contrast-enhanced ultrasonography (CEUS) in hepatic artery pseudoaneurysm (HAP) after liver transplantation was investigated. From January 2005 to November 2015, information was collected on 2,085 cases of orthotopic liver transplantation. The cases included 1,617 men and 468 women. Common ultrasound and CEUS were used to monitor arterial blood flow following surgery, and the complications were assessed. Instruments used included Acuson Sequoia 512 and Mylab Twice, and the contrast agent was SonoVue. The standard of common ultrasound in the diagnosis of HAP was follicular structure, which had arterial blood flow signal present beside the hepatic artery. The diagnostic criteria of HAP using CEUS were abnormal and round contrast enhancement zone and perfusion of the contrast agent in the zone near the hepatic artery. The diagnostic standard of HAP was computed tomographic angiography (CTA) and emergency operation. Eight cases of HAP were diagnosed in 2,085 patients after liver transplantation $(0.38 \%)$. Three cases of HAP were diagnosed successfully by common ultrasound while 5 cases were missed. Sensitivity, specificity and diagnostic accuracy for common ultrasound was 37.5, 100 and 99.76\%, respectively. Six cases of HAP were diagnosed by CEUS and 2 cases were missed. Sensitivity, specificity and diagnostic accuracy for CEUS was 75, 100 and 99.9\%, respectively. Collectively, CEUS is a convenient and effective diagnostic method for HAP following liver transplantation, the diagnostic sensitivity was obviously higher than that of the common ultrasound, and it was more convenient than CTA. Nevertheless, the diagnosis of pseudoaneurysm with deep location, and unsatisfactory grayscale images were easily missed.
\end{abstract}

Correspondence to: Dr Jie Tang, Department of Ultrasound, The General Hospital of Chinese People's Liberation Army, 28 Fuxing Road, Beijing 100853, P.R. China

E-mail: tang_jie_111@163.com

Key words: liver transplantation, hepatic artery pseudoaneurysm, contrast-enhanced ultrasound, ultrasound

\section{Introduction}

Hepatic artery pseudoaneurysm (HAP) after liver transplantation is a rare and serious vascular complication. Pseudoaneurysm rupture and hemorrhage may endanger the life of the patients $(1,2)$. A timely and accurate diagnosis prior to aneurysm rupture has been shown to be favorable for HAP prognosis. Common ultrasound is the preferred examination method of imaging following liver transplantation. Contrast-enhanced ultrasonography (CEUS) is a new technology with the ability of carrying out microvascular imaging $(3,4)$. This method is real-time and convenient and can be considered as a type of point-of-care test (POCT). Advantages of CEUS make it a more efficient method compared with computed tomography (CT), magnetic resonance imaging (MRI) and digital subtraction angiography (DSA).

In the present study, the diagnostic value of common ultrasound was compared to the CEUS in HAP subsequent to liver transplantation. The results showed that, CEUS is a convenient and effective diagnostic method for HAP following liver transplantation.

\section{Patients and methods}

Clinical data. From January 2005 to November 2015, information on 2,085 cases of orthotopic liver transplantation was collected from the Organ Transplantation Research Institute, General Hospital of Chinese People's Armed Police Forces (Beijing, China). The cases included 1,617 men and 468 women. The present study was approved by the Ethics Committee of the General Hospital of Chinese People's Armed Police Forces. Written informed consent for the CEUS examination was obtained.

Instrument and contrast agent. Acuson Sequoia 512 (Siemens Medical Solutions, Mountain View, CA, USA) with contrast pulse sequencing imaging software and Mylab Twice (Esaote S.p.A., Genoa, Italy) with CnTI imaging software were used. SonoVue (Bracco Imaging S.p.A., Milan, Italy) was used as the contrast agent. Peripheral venous infusion was applied after conventional configuration. Physiological saline $(5 \mathrm{ml})$ 
Table I. Imaging diagnosis and clinical treatment for 8 cases with HAP.

\begin{tabular}{|c|c|c|c|c|c|c|}
\hline Cases & $\begin{array}{l}\text { Occurrence } \\
\text { time }\end{array}$ & $\begin{array}{l}\text { Common } \\
\text { ultrasound }\end{array}$ & $\begin{array}{l}\text { Contrast-enhanced } \\
\text { ultrasonography }\end{array}$ & $\begin{array}{l}\text { Clinical } \\
\text { manifestation }\end{array}$ & Treatment & Prognosis \\
\hline 1 & 29 & $\begin{array}{l}\text { Definite } \\
\text { diagnosis }\end{array}$ & $\begin{array}{l}\text { Definite } \\
\text { diagnosis }\end{array}$ & $\begin{array}{l}\text { Intra-abdominal } \\
\text { hemorrhage }\end{array}$ & $\begin{array}{l}\text { Emergency arterial } \\
\text { embolization }\end{array}$ & Lateral shoot formation \\
\hline 2 & 15 & $\begin{array}{l}\text { Definite } \\
\text { diagnosis }\end{array}$ & $\begin{array}{l}\text { Definite } \\
\text { diagnosis }\end{array}$ & $\begin{array}{l}\text { Intra-abdominal } \\
\text { hemorrhage }\end{array}$ & $\begin{array}{l}\text { Tumor resection and } \\
\text { artery reconstruction }\end{array}$ & Well \\
\hline 3 & 44 & $\begin{array}{l}\text { Definite } \\
\text { diagnosis }\end{array}$ & $\begin{array}{l}\text { Definite } \\
\text { diagnosis }\end{array}$ & Hemobilia & $\begin{array}{l}\text { Tumor resection and } \\
\text { hepatic artery ligation }\end{array}$ & $\begin{array}{l}\text { Lateral shoot formation } \\
\text { and biliary complication }\end{array}$ \\
\hline 4 & 38 & $\begin{array}{c}\text { Missed } \\
\text { diagnosis }\end{array}$ & $\begin{array}{l}\text { Definite } \\
\text { diagnosis }\end{array}$ & None & No treatment & Well \\
\hline 5 & 45 & $\begin{array}{c}\text { Missed } \\
\text { diagnosis }\end{array}$ & $\begin{array}{l}\text { Definite } \\
\text { diagnosis }\end{array}$ & None & No treatment & Well \\
\hline 6 & 25 & $\begin{array}{c}\text { Missed } \\
\text { diagnosis }\end{array}$ & $\begin{array}{l}\text { Definite } \\
\text { diagnosis }\end{array}$ & None & $\begin{array}{l}\text { Tumor resection and } \\
\text { artery bypass reconstruction }\end{array}$ & Well \\
\hline 7 & 12 & $\begin{array}{c}\text { Missed } \\
\text { diagnosis }\end{array}$ & $\begin{array}{c}\text { Missed } \\
\text { diagnosis }\end{array}$ & $\begin{array}{l}\text { Intra-abdominal } \\
\text { hemorrhage }\end{array}$ & $\begin{array}{l}\text { Tumor resection and } \\
\text { hepatic artery ligation }\end{array}$ & $\begin{array}{l}\text { Hepatic } \\
\text { retransplantation }\end{array}$ \\
\hline 8 & 18 & $\begin{array}{c}\text { Missed } \\
\text { diagnosis }\end{array}$ & $\begin{array}{c}\text { Missed } \\
\text { diagnosis }\end{array}$ & $\begin{array}{l}\text { Intra-abdominal } \\
\text { hemorrhage }\end{array}$ & Abdominal laparotomy & Death \\
\hline
\end{tabular}

The occurrence time was the time after liver transplantation, unit: day.

was flushed quickly, and a single dose of 0.5-2.4 ml/time was applied.

Inspection method. Conventional ultrasound examination after surgery was conducted on all liver transplant recipients to observe the echo of liver parenchyma and the vascular hemodynamic of all anastomotic vessels. The recipients were checked once per day within a week and after one week they were checked once every 3-7 days until the discharge. Examination frequency for CEUS was 1-2 weeks after the operation, and once when abnormal arterial blood flow parameters were detected. Enhanced CT was performed prior to discharge from hospital, or when abnormal arterial blood flow parameters were detected during ultrasound and contrast-enhanced ultrasound. Observation on hepatic artery included the echo of the hepatic artery, the artery line, the peak velocity, the resistance index and the acceleration time. Abnormal blood flow parameters of hepatic artery were: peak velocity $<25 \mathrm{~cm} / \mathrm{sec}$, RI $<0.5$, and/or SAT $>80 \mathrm{msec}$.

The diagnostic standard for HAP by common ultrasound involved follicular structure with disrupted blood flow and arterial blood flow signal existed along and around the hepatic artery. The diagnostic standard for HAP by CEUS was carried out as: After peripheral intravenous injection with contrast agent and hepatic artery infusion with contrast agent, the contrast agent perfusion in the follicular contrast enhancement zone beside the hepatic artery synchronized with the perfusion in hepatic artery, and it was visible that the contrast agent was sprayed from the artery to a vesicle-like structure along with the arterial pulse.

Diagnostic gold standard. The diagnostic gold standard of HAP after liver transplantation was CT angiography (CTA) or operation. Six cases of HAP were diagnosed by CTA, and 2 cases were confirmed by emergency operation.
Statistical analysis. PASW Statistics 18.0 SPSS 18.0 (SPSS, Inc., Chicago, IL, USA) was used for statistical analysis.

\section{Results}

Imaging diagnosis. Of the 2,085 patients, 8 cases of HAP following liver transplantation were diagnosed $(0.38 \%)$. There were 7 men and 1 woman. The condition occurred 12-44 days after the operation (average time, 28.3 days). Clinical manifestation and imaging diagnosis of the 8 cases of HAP is shown in Table I. Three HAP cases were diagnosed using common ultrasound while 5 cases were missed. Sensitivity, specificity and diagnostic accuracy for this method was 37.5, 100 and $99.76 \%$, respectively. In total, 6 cases of HAP were diagnosed using CEUS while only 2 cases were missed. Sensitivity, specificity and diagnostic accuracy for CEUS method was 75,100 and $99.9 \%$, respectively.

Hepatic artery pseudoaneurysm in hepatic artery anastomosis. Of the 8 cases of HAP, 3 cases were definitely diagnosed by the two methods, follicular structure was visible in hilar through grayscale ultrasound, arterial blood flow signal was detected during color Doppler ultrasound, and CEUS showed synchronous enhancement of contrast agent in a vesicle-like structure and the hepatic artery (Fig. 1). Three cases that were not diagnosed correctly by common ultrasound, were diagnosed by CEUS. In 2 of 3 cases, follicular structure was invisible in hilar through grayscale ultrasound, color Doppler ultrasound showed RI $<0.5$ and SAT $>80 \mathrm{msec}$ in hepatic artery, and CEUS showed that synchronous enhancement of contrast agent in the vesicle-like structure and the hepatic artery (Fig. 2).

In another case, the postoperative clinical manifestation was multiple biliary tract hemorrhage. During the first examination on the 38th day after operation, we observed no 

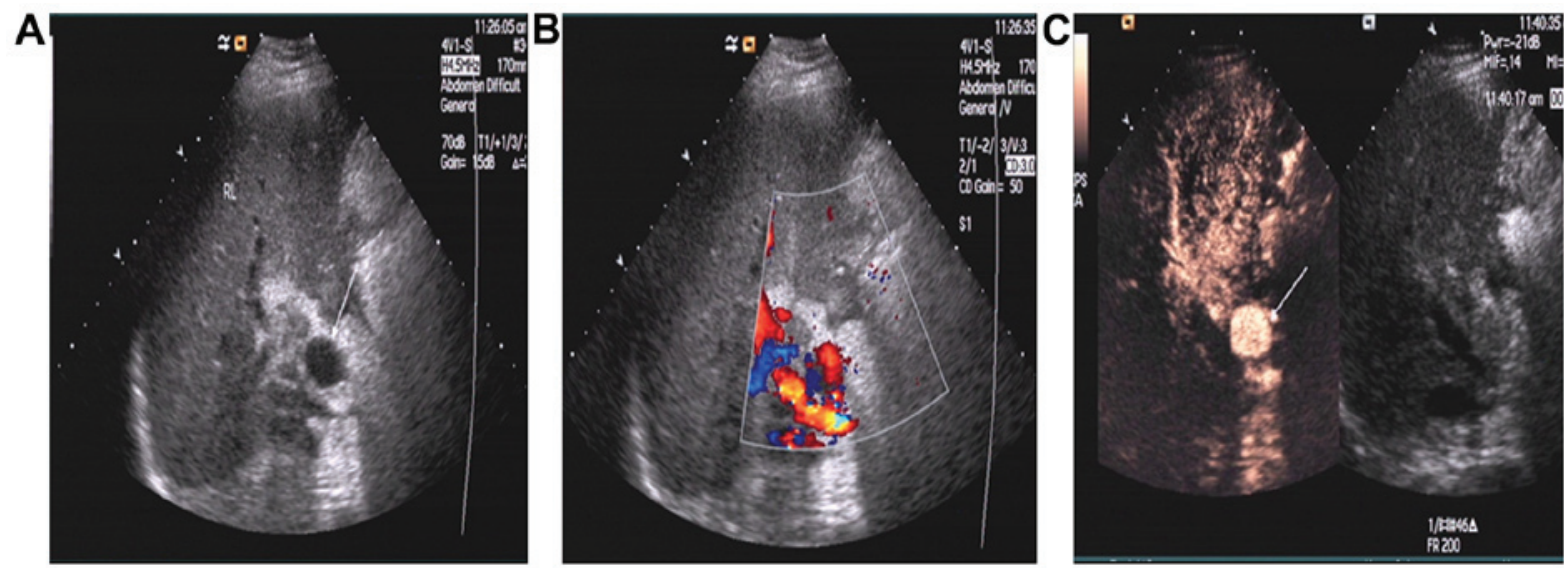

Figure 1. Hepatic artery pseudoaneurysm in hepatic artery anastomosis. (A) Grayscale ultrasound shows hilar cystic structure in hilar (white arrow). (B) Color Doppler ultrasound shows there are arterial blood flow signals in cystic structure. (C) Contrast-enhanced ultrasonography showing the arterial phase; angiography and perfusion in the cystic structure (white arrow) were evident, SonoVue dosage: $1.5 \mathrm{ml} /$ time.
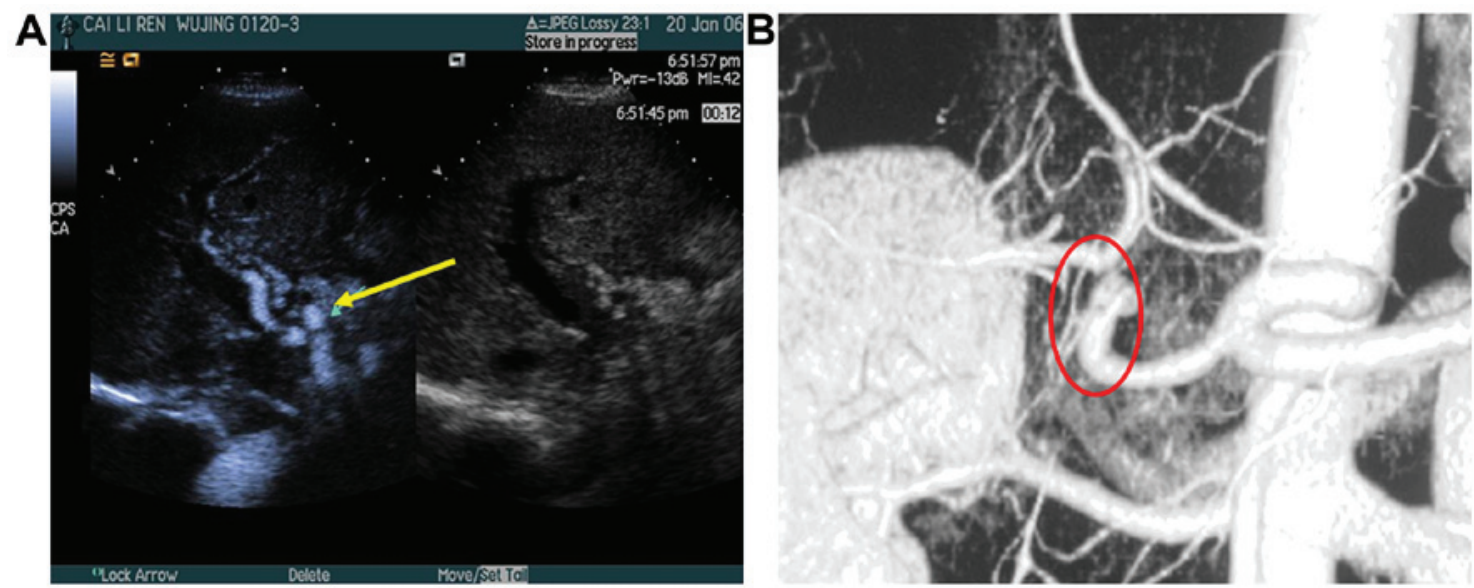

Figure 2. Hepatic artery pseudoaneurysm. (A) Contrast-enhanced ultrasonography shows the tumor around the hepatic artery (yellow arrow), SonoVue dosage: $1.5 \mathrm{ml} /$ time. (B) CTA shows hepatic artery pseudoaneurysm, in red circle, the spherical shape around the hepatic artery.
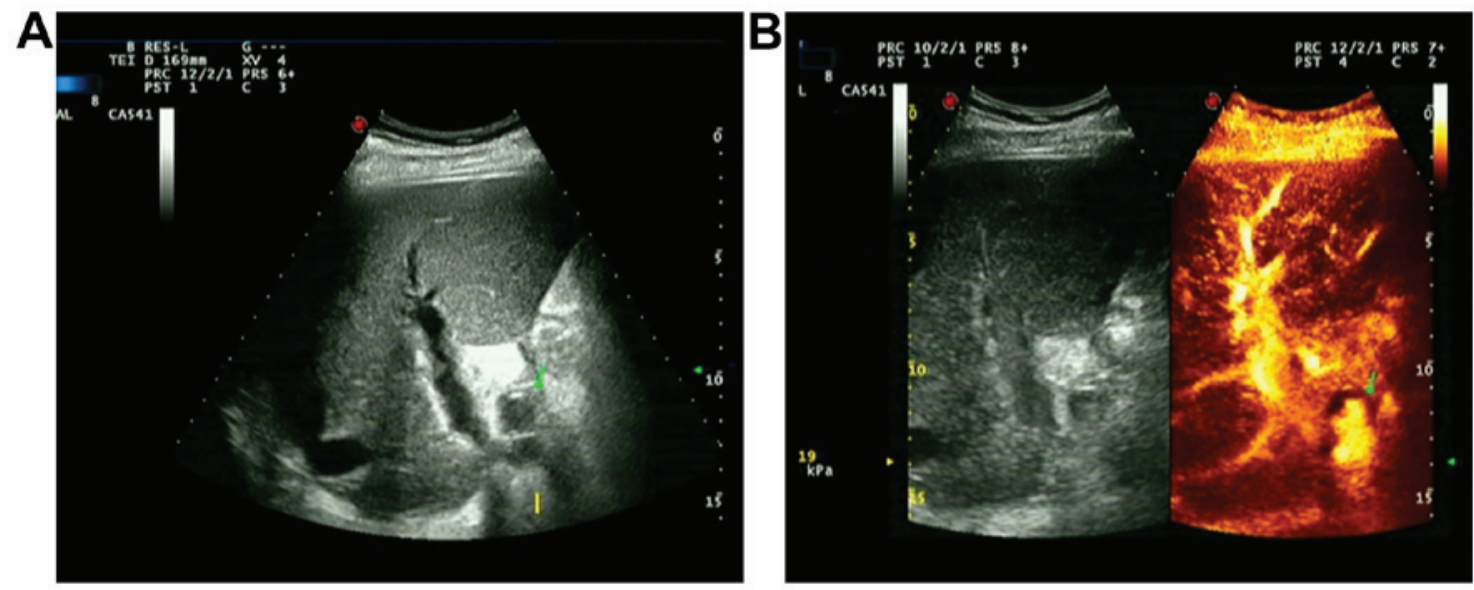

Figure 3. Hepatic artery pseudoaneurysm. (A) Grayscale ultrasound shows a hypoechoic mass in the hilar (green arrow) and (B) contrast-enhanced ultrasonography shows contrast agent perfusion in pseudoaneurysm (green arrow). Dosage of the contrast agent was $1.5 \mathrm{ml} /$ time.

abnormal echo in hilar during grayscale ultrasound and no significantly abnormal hepatic artery blood flow parameters. During the second examination on the 44th day after surgery, low echo area was detected in hilar by common ultrasound and no blood flow signal was detected during the examination with color Doppler ultrasound. With CEUS, in low echo area, the contrast agent sprayed into tumors along with arterial pulse, and gradually filled them (Fig. 3). There were 2 HAP cases that 
were not diagnosed by common ultrasound or CEUS. There was a single case that was diagnosed by CTA. The position of HAP was far from the hilar. The other case was confirmed by emergency surgery due to abdominal bleeding.

\section{Discussion}

Liver transplantation is the only effective treatment for patients suffering from terminal stages of liver disease. Postoperative arterial complications are the most important factors affecting the success of the transplant $(5,6)$. The most common hepatic artery complications are hepatic artery stenosis, embolization, hepatic artery dissection and HAP (7-10). HAP is the rarest and most dangerous complication with an incidence rate of $0.5-2.6 \%(11,12)$. HAP may lead to mortality due to rupture and hemorrhage. The mortality rate, after liver transplantation, due to HAP is extremely high (2.7\%). Timely detection, diagnosis and treatment can effectively reduce the mortality rate $(1,13)$.

The preferred method of blood flow monitoring after liver transplantation is the common ultrasound (14), CTA, MRI and DSA. Other large equipment cannot be used for POCT, and are often applied as supplementary examination and qualitative diagnosis. CT, MRI and DSA are not routine examinations, and are usually applied prior to hospital discharge or in the event of a possible vascular complication following ultrasonic examination. In this study, we used CEUS as a postoperative routine imaging examination method. CEUS, has been widely used for the differential diagnosis of abdominal organs with space-occupying lesion $(15,16)$, and it has also been applied for the diagnosis of vascular complications following liver transplantation (17-19). Ultrasound contrast agent, which also served as a blood pool tracer, can be used in real-time ultrasound contrast imaging to identify large blood vessels and the micro-vascular system (20).

HAP mostly occurs in the anastomotic site, and is often linked to infection, bile leakage or multiple TACE treatment prior to transplantation. Certain technical difficulties are involved in the detection of arterial anastomosis with common ultrasound. HAP, which is located near the hilar, possessing disrupted artery blood fow, was lined with the artery, and common ultrasound was able to make a diagnosis (21), as in the 3 cases of HAP diagnosed using common ultrasound in the study. Detection of anastomosis is difficult when located far from the hilar. This is due to the interference caused by gas, intestine and omentum. In this study, 3 cases of HAP that were far from the hilar, demonstrated abnormal hemodynamic parameters in the common ultrasound examination. CEUS successfully diagnosed 2 of the cases, while the other one was diagnosed by CTA. In the HAP cases, during examination with CEUS, we observed a circular contrast agent perfusion area around the artery after the perfusion of contrast agent.

In one case of HAP, the diagnosed primary diseases were liver cirrhosis and hepatocellular carcinoma. TACE was performed 6 times prior to operation and postoperative clinical manifestations were two occasions of biliary tract hemorrhage. In the first biliary tract hemorrhage, common ultrasound showed no abnormalities while in the second one, grayscale ultrasound identified a hilar hypoechoic mass. Color Doppler ultrasound did not identify any sign of blood flow in lumps.
CEUS showed that, in the arterial phase, contrast agent was sprayed into the tumor with arterial pulse in the low echoic block. Emergency laparotomy was carried out and tumor resection and arterial ligation were conducted under the guidance of ultrasound. During the operation, we detected a large tumor with high probability to rupture and cause hemorrhage.

If the surgery had been delayed the patient would have faced a life-threatening condition. The case was analyzed to determine the reason for the failure of color Doppler ultrasound to detect any blood flow signal in the tumor leading to missed diagnosis. We hypothesized that the failure was due to the presence of a smaller fistula orifice between the HAP and hepatic artery that retarded the blood flow.

Ultrasound contrast agents belong to the blood pool tracers and mimic the blood flow. Contrast agent perfusion also occurs, and thus ultrasound has a function of diagnosis. It was reported that multiple TACE prior to liver transplantation in liver cancer cases may increase the risk of HAP following liver transplantation (22). Therefore, for liver transplantation recipients with multiple TACE treatment, any of the following symptoms suggest a high risk for occurrence of HAP: i) Biliary tract bleeding; ii) bile leakage; and iii) abdominal bleeding. In these cases, the best course of action would be performing ultrasound angiography, CTA or DSA as early as possible to avoid missed diagnosis.

CTA, MRI and DSA were not used as routine examination methods of vascular complications after liver transplantation. Therefore when postoperative common ultrasound detects any of these conditions, CEUS or other vascular imaging should be conducted to verify: i) Arterial hemodynamic abnormalities; ii) follicular block; and iii) low echoic lump in hilar. The treatment of HAP should be proactive, whenever possible, and arterial revascularization treatment should be immediately carried out to avoid tumor rupture. In the present study, only 1 of 8 cases of HAP succumbed, and this may be attributed to the timely diagnosis of CEUS and timely surgical intervention.

In summary, CEUS was identified as a convenient and effective diagnostic method for HAP cases following liver transplantation. This is a superior method of diagnosis compared with CTA, as it can be realized in real-time and is considered more convenient. Poor grayscale image display affected the display effect of CEUS. For HAP located far from the hilar, there was a high probability of missed diagnosis. CEUS made up for the deficiencies associated with enhanced CT, DSA and other large equipment, and was crucial in the diagnosis of vascular complications subsequent to liver transplantation.

\section{References}

1. Volpin E, Pessaux P, Sauvanet A, Sibert A, Kianmanesh R, Durand F, Belghiti J and Sommacale D: Preservation of the arterial vascularisation after hepatic artery pseudoaneurysm following orthotopic liver transplantation: Long-term results. Ann Transplant 19: 346-352, 2014.

2. Nghiem HV: Imaging of hepatic transplantation. Radiol Clin North Am 36: 429-443, 1998.

3. Luo Y, Fan YT, Lu Q, Li B, Wen TF and Zhang ZW: CEUS: A new imaging approach for postoperative vascular complications after right-lobe LDLT. World J Gastroenterol 15: 3670-3675, 2009.

4. Rennert J, Dornia C, Georgieva M, Roehrl S, Fellner C, Schleder S, Stroszczynski C and Jung EM: Identification of early complications following liver transplantation using contrast enhanced ultrasound (CEUS). First results. J Gastrointestin Liver Dis 21: 407-412, 2012 . 
5. Wertheim JA, Petrowsky H, Saab S, Kupiec-Weglinski JW and Busuttil RW: Major challenges limiting liver transplantation in the United States. Am J Transplant 11: 1773-1784, 2011.

6. Pakosz-Golanowsha M, Lubikowski J, Post M, Jarosz K, Zasada-Cedro K, Milkiewicz P and Wójcicki M: The arterial anastomosis in liver transplantation: Complications, treatment and outcome. Hepatogastroenterology 57: 1477-1482, 2010.

7. Singhal A, Stokes K, Sebastian A, Wright HI and Kohli V: Endovascular treatment of hepatic artery thrombosis following liver transplantation. Transpl Int 23: 245-256, 2010.

8. Yang Y, Zhao JC, Yan LN, Ma YK, Huang B, Yuan D, Li B, Wen TF, Wang WT, Xu MQ, et al: Risk factors associated with early and late HAT after adult liver transplantation. World J Gastroenterol 20: 10545-10552, 2014.

9. Frongillo F, Lirosi MC, Nure E, Inchingolo R, Bianco G, Silvestrini N, Avolio AW, De Gaetano AM, Cina A, Di Stasi C, et al: Diagnosis and management of hepatic artery complications after liver transplantation. Transplant Proc 47: $2150-2155,2015$

10. Hamby BA, Ramirez DE, Loss GE, Bazan HA, Smith TA, Bluth E and Sternbergh WC III: Endovascular treatment of hepatic artery stenosis after liver transplantation. J Vasc Surg 57: 1067-1072, 2013

11. Fistouris J, Herlenius G, Bäckman L, Olausson M, Rizell M, Mjörnstedt L and Friman S: Pseudoaneurysm of the hepatic artery following liver transplantation. Transplant Proc 38: 2679-2682, 2006.

12. Saad WE, Dasgupta N, Lippert AJ, Turba UC, Davies MG, Kumer S, Gardenier JC, Sabri SS, Park AW, Waldman DL, et al: Extrahepatic pseudoaneurysms and ruptures of the hepatic artery in liver transplant recipients: Endovascular management and a new iatrogenic etiology. Cardiovasc Intervent Radiol 36: 118-127, 2013.

13. Thorat A, Lee CF, Wu TH, Pan KT, Chu SY, Chou HS, Chan KM, Wu TJ and Lee WC: Endovascular treatment for pseudoaneurysms arising from the hepatic artery after liver transplantation. Asian J Surg: Aug 30, 2014 (Epub ahead of print).
14. Girometti R, Como G, Bazzocchi M and Zuiani C: Post-operative imaging in liver transplantation: State-of-the-art and future perspectives. World J Gastroenterol 20: 6180-6200, 2014.

15. Tada T, Kumada T, Toyoda H, Ito T, Sone Y, Kaneoka Y, MaedaA, Okuda S, Otobe K and Takahashi K: Utility of contrast enhanced ultrasonography with perflubutane for determining histologic grade in hepatocellular carcinoma. Ultrasound Med Biol 41: 3070-3078, 2015.

16. D'Onofrio M, Crosara S, De Robertis R, Canestrini S and Mucelli RP: Contrast-enhanced ultrasound of focal liver lesions. AJR Am J Roentgenol 205: W56-W66, 2015.

17. Fontanilla T, Noblejas A, Cortes C, Minaya J, Mendez S, Van den Brule E, Hernando CG, Alfageme M, Baños I and Aguirre E: Contrast-enhanced ultrasound of liver lesions related to arterial thrombosis in adult liver transplantation. J Clin Ultrasound 41: 493-500, 2013.

18. Zheng RQ, Mao R, Ren J, Xu EJ, Liao M, Wang P, Lu MQ, Yang Y, Cai CJ and Chen GH: Contrast-enhanced ultrasound for the evaluation of hepatic artery stenosis after liver transplantation: Potential role in changing the clinical algorithm. Liver Transpl 16: 729-735, 2010.

19. Lee SJ, Kim KW, Kim SY, Park YS, Lee J, Kim HJ, Lee JS, Song GW, Hwang S and Lee SG: Contrast-enhanced sonography for screening of vascular complication in recipients following living donor liver transplantation. J Clin Ultrasound 41: 305-312, 2013.

20. Cosgrove D and Harvey C: Clinical uses of microbubbles in diagnosis and treatment. Med Biol Eng Comput 47: 813-826, 2009.

21. Sanyal R, Zarzour JG, Ganeshan DM, Bhargava P, Lall CG and Little MD: Postoperative Doppler evaluation of liver transplants. Indian J Radiol Imaging 24: 360-366, 2014.

22. Goel A, Mehta N, Guy J, Fidelman N, Yao F, Roberts J and Terrault N: Hepatic artery and biliary complications in liver transplant recipients undergoing pretransplant transarterial chemoembolization. Liver Transpl 20: 1221-1228, 2014. 